\title{
Branding of Prescription and Non-prescription Drugs
}

Merve Memişoğlu ${ }^{1^{*}}$

'Biruni University, Faculty of Pharmacy, Department of Pharmacy Management, 34010 Istanbul, Turkey

\begin{abstract}
It is worthwhile to note that, while health related products are mostly function driven categories, health in itself is an emotive and personal subject. With this perspective, pharmaceutical companies need to focus on understanding the importance of branding in this rapidly changing social behaviour, competitive landscape, communication tools and techniques.

Although branding in the pharmaceutical industry has been changing for the past decade, major issues for industry stakeholders like healthcare professionals and patients are still ethical communication and marketing strategies. For pharmaceutical branding, companies should be engaged with related stakeholders in an effective and ongoing way while complying with regulations.

The purpose of this review is to evaluate the importance of branding for pharmaceuticals and underline the sentimental and functional benefits to consumers and/ or patients. The focus of this review lies on branding and marketing communication process of pharmaceutical products and also providing insight for further pharmaceutical branding studies.
\end{abstract}

Keywords: OTC, over-the-counter drugs, prescription drugs, pharmaceutical marketing, pharmaceutical branding.

\section{INTRODUCTION}

\section{What is Brand and Branding?}

There are multiple definitions to this question, but according to the American Marketing Association (AMA), brand is defined as follows; "a brand is a name, term, design, symbol, or any other feature that identifies one seller's good or service as distinct from those of other sellers." product different and easily identifiable. A successful brand also survives the rest of time or "can be timeless" as quoted by Stephen King.

There are other definitions; Kotler et al. explained as "the brand creates value to the customers and can also become a competitive advantage for the company." 2 .

*Corresponding author: Merve Memişoğlu, e-mail: mmerve.memisoglu@gmail.com, Tel: +904448276 (Received 23 October 2017, accepted 8 November 2017) 
Schuiling and Moss also described a brand as "a name that will register the product in the consumers mind as a set of tangible and intangible benefits."3.

Brand strategy is how, what, where, when and to whom they plan on communicating and delivering on the brand messages. In order to build a brand, companies must develop a brand strategy. Brand strategy building blocks include: brand positioning, brand personality, brand values, brand appears and perceived qualities which are based on product features such as reliability ${ }^{4-5}$.

A brand can be divided into six different levels as attributes, benefits, values, culture, personality and user ${ }^{2}$. The value is recognised as one of the most vital part of branding, which in itself has three types: functional, expressive and central values. Normally, successful brands have a combination of value types ${ }^{3,6-7}$.

Currently, people demand to be treated as whole human beings with minds, hearts, and spirits. Therefore brands should especially meet consumers deeper needs for social, economic, and environmental justice ${ }^{8}$.

Kotler described brand meanings through different levels as listed in Table $1^{9}$.

Table 1. Brand Meaning Levels ${ }^{9}$

\begin{tabular}{|c|c|}
\hline Meaning Levels & Description \\
\hline Attributes & Certain attributes that come to mind. \\
\hline Benefits & Attributes must be translated into functional and emotional benefits. \\
\hline Values & The brand says something about the manufacturer's value. \\
\hline Culture & The brand may represent a certain culture. \\
\hline Personality & The brand can project a certain personality. \\
\hline User & The brand suggests the kind of customer who buys or uses the product. \\
\hline
\end{tabular}

Brand development journey often involves a combination of elements to co-exist like; a good name, recognisable logo, a slogan, a symbol, jingles, packaging, shape and colour. For example; a good slogan or jingle can help the brand to be kept in customers' mind. Together these elements contribute to the brand identity ${ }^{10}$.

Possible benefits of branding are listed by Hoeffler and Keller ${ }^{11-12}$ include the following attributes;

- improved perceptions of product performance;

- increased customer loyalty;

- less vulnerability to competitive marketing actions and marketing crises;

- larger margins; 
- elastic customer response to price changing;

- greater trade or intermediary cooperation and support;

- increased marketing communication effectiveness;

- additional licensing and brand extension opportunities.

Branding is not only prominent for pharmaceutical products but also for other healthcare products such as probiotics and prebiotics ${ }^{13}$.

\section{What are the Differences Between Pharmaceutical and Fast-Moving Consumer Goods (FMCG) Industry?}

The pharmaceutical industry is associated with a strong $\mathrm{R} \& \mathrm{D}$ as well as extensive sales force. Yet in time the pharmaceutical industry has been facing several challenges which include high cost of $\mathrm{R} \& \mathrm{D}$, the patent expiration of products in parallel with the erosion of price and consolidating of the pharmaceutical companies?

A schematic perspective outlining the difference between the pharmaceutical industry and the FMCG industry would be as below;

PHARMA BRANDS

Effort

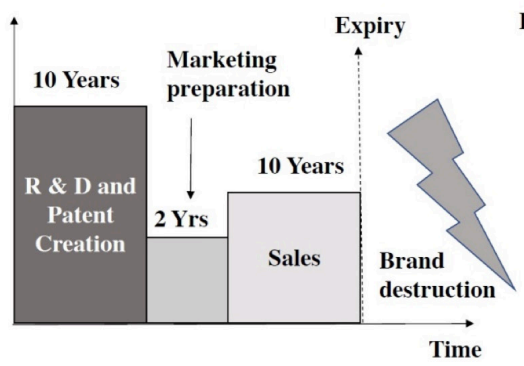

FMCG BRANDS

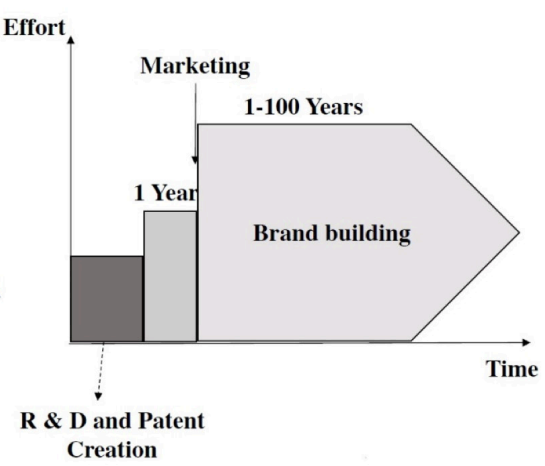

Figure 1. Differences between Pharma and FMCG brands ${ }^{14}$

The pharmaceutical industry has strict regulations. For this reason, a new product launch into the market is quite slow. Pharmaceutical products have relatively short-term patent protection. After patent expiration, pharmaceutical brands cannot be transferred in contrary to FMCG products. While brands of prescription drugs survive max 10 years, brands of non-prescription drugs can continue for a long time like FMCG products (Figure 1).

Given today's technology and sciences, when a new molecule discovery is made, which is more effective for a certain treatment, existing brands lose their importance ${ }^{6}$. Weston has suggested that 'super brands' are capable of surviving patent 
expiration and can achieve "a bond with the consumer at a level transcending mere functional performance" $"$.

Conversely, FMCG companies integrate brand development early in the product development cycle. The difference thereby is pharmaceutical companies focus on developing products rather than the brand. The latter have not been as efficient in using the power of brands. Yet, in certain markets like United States, certain OTC products have extensive advertising campaigns. This factor has led Moss and Schuiling to claim that branding in pharmaceuticals is ten years behind the FMCG industry .

Brand building is a long-term process and advertising is one of the key aspects. Within this concept, new strands have emerged in certain markets like that of direct to consumer advertising (DTCA). The advertising of prescription drugs is banned in a large extent of countries. The United States and New Zealand are the only countries that allow DTCA on television and other broadcasting media for prescription drugs where the consumer has little choice in drug selection ${ }^{16}$. Canada also does not allow advertisement which cover both the product and related indication ${ }^{17-18}$.

In countries like Turkey where DTCA is not allowed, marketing activities of prescription drugs are based on functional attributes of products such as clinical and product related features. Promotion is directed primarily at healthcare professionals and includes several marketing activities such as personal sale, drug detailing, advertising in journals and medical administration software, sponsoring educational events, educational materials, promotional merchandise, public relations activities and disease awareness campaigns (DACs) ${ }^{19}$.

Conversely, the regulatory restrictions are waived for OTC or non-prescription drugs as the consumer has direct access right to choose. Regarding OTC, products are allowed to be advertised to the public. OTC branding is similar to FMCG branding at many points and the aim of branding is to achieve brand recognition, brand preference and brand loyalty, increase market share accordingly.

End consumers are an important part of the purchase decision for OTC drugs making the role of brands very significant. Promotion is directed towards consumers/patients as well as healthcare professionals and includes several marketing activities such as DTCA (including TV, radio, print ads, etc.), detailing, sponsorship, events, direct mail, promotional merchandise, public relations activities, social media and viral marketing. For the OTC marketers, the most important question should be what the audience needs because brand association or brand image comes from customers' needs. 
Table 2: Differences between Pharma and FMCG brand building7,14

\begin{tabular}{ll}
\hline FMCG & Pharmaceuticals \\
\hline Focus on brand creation & Focus on product creation \\
\hline Long time- decades & Short time-months, years \\
\hline Lifecycle doesn't need to exist & Lifecycle management necessary \\
\hline Marketing effort create the brand & R\&D effort create the product \\
\hline Investment maintains the brand & Patent expiry signals loss of resources \\
\hline Brand destruction does not exist, & Product cast out to provide revenue for new products \\
portfolio rationalization does & \\
\hline The brand is the asset & The product is the asset \\
\hline Strategy and brand management & R \& D and sales management \\
\hline Brand name can be transferred & $\begin{array}{l}\text { Brand name cannot be transferred to another molecule } \\
\text { following patent expiry }\end{array}$ \\
\hline $\begin{array}{l}\text { The end users are simply the } \\
\text { consumers }\end{array}$ & $\begin{array}{l}\text { Doctor and pharmacists represent an additional layer } \\
\text { between patient and company }\end{array}$ \\
\hline
\end{tabular}

Regarding the brand name strategy, FMCG sector adopts three basic brand name strategies. These names are descriptive brand, new brand and corporate brand.

Conversely, pharmaceutical brand name strategies utilise differing focus points. These range from the scientific name of the active substance (Indocin for Indomethacin), the therapy (Procardia), the indication (Glucophage), the class (Mevacor/Zocor) the corporate name (Novarapid-Novo Nordisk) and a new brand name (Zantac, Prozac).

Except the well known corporate and new brands, pharmaceutical brand name could be imitated and generics can threaten the brand name, image or positioning easily ${ }^{7}$. In some cases, corporate and product brand names may be closely associated which could impact each other and thus care must be taken in brand management. For example, the Merck corporate brand was negatively affected following the withdrawal of nonsteroidal anti-inflammatory drug Vioxx ${ }^{7}$.

The benefits of branded pharmaceuticals towards different stakeholders such as prescriber, patient, payer and manufacturer are listed below according to Dogramatzis $^{20}$. 
Table 3. The benefits of branded pharmaceuticals ${ }^{20}$

\begin{tabular}{llll}
\hline Prescriber & Patient & Payer & Manufacturer \\
\hline Efficacy & Efficacy & Efficacy & Competitive advantage \\
Risk reduction & Risk reduction & Safety & Easier segmentation \\
Trust & Trust & Standardization & Global marketing \\
Patient retention & More information & Risk reduction & Customer loyalty \\
More information & Feeling good & Trust & Product bundling \\
Sponsorships & Convenience & Economies of & Easier line extensions \\
& Easier comparisons & sale & Shorter time to market \\
& Company accountability & & Image building \\
& & & Premium pricing \\
& & & Employee morale \\
\hline
\end{tabular}

\section{Pharmaceutical Environment}

To understand pharmaceutical branding, we should evaluate the environment of the pharmaceutical companies first.

Bendarik $\mathrm{k}^{21}$ mentioned in his article that the pharmaceutical industry is affected by several political, economic, social, technological, legal and environmental factors. It is believed that the most remarkable among them are social, technological and legal factors. Legal factors involve issues regarding patent protection and all regulation processes. It is a rather short period of time for companies to build the business of their product before the generic drugs capture the market. The market is highly regulated in every aspect.

Social factors cover the trends of aging population, self-medication, a desire to increase the life expectancy and most common chronic diseases such as diabetes or cardiac diseases. Therefore, pharmaceutical companies are building on the development of new drugs meant to target population and specific diseases ${ }^{21}$.

With social and technological changes, it would appear that the consumers are becoming more educated and capable. With information everywhere, the consumer and patient is, able to drill deeper to seek; manufacturer details and product comments by others. To counter this information thirst and to create trust, manufacturers are disclosing more corporate aspects like sustainability, corporate responsibility and employee working conditions ${ }^{22}$.

With change in corporate and consumer attitudes, the media sector has also changed dramatically. The new trend or communication medium is clearly the internet and social media as opposed to traditional channels like TV, radio, newspaper.

As the internet is becoming a much more powerful vehicle for branding and communications, the role of mass media is becoming less effective ${ }^{12,23-24}$. 
With the internet, interactivity between stakeholders, especially corporate and patient/consumer, are increasing. Within this framework, the use of social networks, mobile application platforms and internet user groups allow users to contribute with brand-related content, and share their experiences and opinions with other consumers anytime and anywhere ${ }^{25}$.

New technologies (including devices and information platforms) like fast adaptation to smart devices is also educating the consumer to rely on self-medication and positively impacting the OTC market $^{26}$.

\section{How Can a Successful Pharmaceutical Brand Be Built?}

While branding creates awareness, brand positioning creates product differentiation. A strong brand creates high consumer loyalty and can influence the behaviour and attitude of patients and healthcare professionals directly ${ }^{3,26}$.

In a survey conducted by Battistoni et all in 2014, it was seen that the benefit of OTC brand is most effective (60\%) in determining consumer behaviour. Among the benefits, the communication strategy has the highest effectiveness. Within which the most prominent element was communication strategies. These strategies ranked advertising first (20.74\%), media coverage second (9.71\%), popular references $(8.83 \%)$ and corporate social responsibility $(7.32 \%)^{27}$.

The fact remains that medical product communication and medical brand communication should not be confused with each other. Because the brand has a more flexible nature than the product, it can easily pass without being affected by environmental factors and barriers/limitations. In contrast, there are risks at various stages of product communication ${ }^{28}$.

The power of branding has two assets. First, a powerful brand is borderless- can cross the borders and markets. Second, a powerful brand can also influence behaviour and attitudes. For example; Prozac has acquired almost iconic status with the term of 'Prozac generation' since introduction of Prozac to the market in the late 1980 .

From the perspective of the pharmaceutical industry, the following functional benefits are significant: 1. Efficacy 2. Safety (minimal adverse effects etc.) 3. Convenience (dosage form, pleasant taste/way related dosage administration etc.) 4 . Cost-effectiveness ${ }^{5}$.

Since, functional benefits are not the only way to encourage brand loyalty, companies must create the need for the consumer to be loyal by touching the consumers in an emotional manner. Next, companies must decide how to communicate these benefits in a consistent way to the target customers. This method 
allows long term brand loyalty by establishing an emotional dialogue with the consumer via a sustained campaign ${ }^{12,29-30}$.

Constitutively one of the most powerful emotional values in the pharmaceutical field is trust. Although trust in pharmaceutical brands is relatively low, once trust is gained, it can be contributed to the brand building process most successfully. A case in point is, the longevity of OTC products, is due to trust build up over the years ${ }^{31}$.

For increasing brand loyalty, companies use several approaches which include education, logistic and reimbursement support. For example; physician-targeted continuing medical education (CME) schemes and patient-targeted disease awareness sites as education examples, such as "For My Bones" program (Novartis) as a logistic example and SHARE@ program (Lundbeck) as an example of reimbursement support ${ }^{32}$.

Another report by Roblek ${ }^{33}$ et al show that consumer satisfaction with safety and product information had a significant effect on consumer trust. In addition to consumer trust, corporate social responsibility (CSR) had also a significant effect on virtual brand loyalty. Consumers can make brand changes according to their corporate social responsibility activities.

Successful brands are those who use a combination of any of the brand elements which include logos, slogans, packaging, names, characters and symbols. Furthermore, according to Pilling ${ }^{34}$, both physicians and patients are more susceptible to pharmaceutical branding activities when they are supported by clinical evidence.

\section{Positioning - The First Step to Branding}

Positioning is the vital step of pharmaceutical branding. The message type does not impact positioning. Both the positive statements (features and benefits) and also negative statements (adverse events, overdose, contraindications and drug interactions) can be used for choosing, targeting and positioning strategies ${ }^{20}$.

The proper positioning has been determined by Dogramatzis as follows ${ }^{20}$;

- Identify competitive products (in both category and brand)

- Identify determinant attributes (Features, benefits, applications)

- Measure existing perceptions (recalls)

- Analyse competitive and relative position of alternatives (prescription, nonprescription)

- Determine preferred set of attributes (customer preference, survey)

- Define positioning (Competitive strengths of different brands)

- Devise repositioning (growth of segments, emerging attributes, new brands, new segments...etc.) 
Within positioning, brand personality is an important differentiating factor. Within advertising the visual identity can include positioning as; masculine or feminine, young or old, radical or conservative, according to visual identity and advertisement ${ }^{4}$.

Overall, the audience must see the combination of the brand name, packaging design and advertising. Brand personality is usually achieved through visual imagery and the use of celebrity endorsements ${ }^{35}$.

\section{Integrated Marketing Communication (IMC) - Speaking with One Voice}

Successful branding ensures a consistent and continuous refined message and it can be possible by integrated marketing communication.

If one can bridge the gap within the audience perceptions hence the gap filler brand communication has achieved its objectives.

According to Kotler IMC is from reliance on one communication tool such as advertising to blending several tools to deliver a consistent brand image to customers at every brand contact ${ }^{9}$.

IMC represents marketing tools, approaches (personalised, customer-oriented, technology-driven) and resources as a whole. All marketing communication must be integrated to create awareness of the brand, to link the brand image in consumers' memory and to facilitate a stronger bond.

Consumers meet the brand through advertising (such as: media advertising; direct response and interactive advertising; place advertising; point- of-purchase advertising), internet marketing, event marketing and sponsorship, direct marketing, database marketing, trade promotions, consumer promotions, publicity, public relations and personal selling ${ }^{36}$.

On the other hand, the digital age has changed marketing channels. TV advertisement lost popularity among consumers especially young people. As time goes on, online and mobile advertising are of growing importance. Consumers can be informed about products and services without the limitations of time and place faced by traditional mass media. Social networks such as Facebook, Twitter, Instagram and LinkedIn have cultivated vast audiences. IMC is the exact key to success in the digital environment.

According to Mulhern, the principles of IMC are consumer insight, data-driven decision making and communications with multiple stakeholders represent an improved framework for managing communications in a digital world ${ }^{37}$. Regarding interactive marketing communication, it includes websites, search ads, dis- 
play ads, videos, sponsorships, on-line communities, e-mail and mobile marketing $^{12}$.

IMC campaigns allow a celebrity speaking about a medical condition. For example; Pfizer first launched a massive advertising and public relations campaign with celebrities for branding Viagra ${ }^{38}$.

There is an increasing trend in Australia, where marketers use "Un-named" product advertisements which were promoted to consumers without the product name and Disease State Awareness (DSA) campaigns which are implemented for brand building 39 .

As it turns out, the disease is also branding by IMC to build public awareness and make the complexities of current and new diseases easier to understand.

Branding is widely used in several health awareness campaigns. For example "truth $®$ " is a national tobacco prevention campaign for youth and young adults via branding techniques. Branded health campaigns differs from other branding activities mainly due to the fact that the brand object is voluntary. Successful health branding has the potential to decrease risky behaviors such as drug abuse, unsafe sex, unhealthy diet etc prominently ${ }^{40}$.

The objectives of "The Heart Truth" as another branding campaign are increasing awareness among women about their risk of heart disease, encouraging women to talk to their doctors, finding out their risk and taking action to reduce them ${ }^{41}$.

Signs and symptoms and their association with the disease play a key role in moving the patient to seek diagnosis and medical help. For example; a pink ribbon to mark breast cancer awareness.

Diseases often gain additional publicity with celebrities undergoing a case history. A recent case is of the Australian pop star Kylie Minogue who recovered after diagnosis with breast cancer or the cyclist Lance Armstrong who fought against testicle cancer ${ }^{42-43}$.

\section{As a Communication Tool, Storytelling}

Storytelling is essential for successful branding. For pharmaceutical companies, storytelling is a relatively hot topic to communicate and share the key insight with different stakeholders. Pharmaceutical companies engage consumers through the art of storytelling. Marketers should provide truth via real patient stories. Marketers should also use social media to listen to patients and to leverage those stories to help motivate other patients and to enhance the image of their brands ${ }^{44-45}$. 
Fog et al. emphasized that today's strong brands are built on clear values and emotional connections with consumers; this is where storytelling comes to use to incorporate brand values into stories, develop emotional bonds with consumers and create consistent brand images ${ }^{46}$.

Storytelling has positive effects on brand attitudes and purchase intentions. Compared to regular advertisements, storytelling can also make a brand more memorable in multiple ways (visually, factually and emotionally) and help to understand the benefits of the brand ${ }^{44,47-50}$.

\section{Direct to Consumer Pharmaceutical Advertisement (DTCPA): The Good or The Bad?}

With the information flow comes noise. Consumers are exposed to too many ads. Synchronously, consumers are paying less attention to the advertisement. The main reasons of this dramatic decrease are that they have lost faith in truthfulness of ad messages and they can access more information using the web among many channels ${ }^{51}$.

There are currently three types of DTC pharmaceutical advertisements; 1) Reminder advertisements (limited information such as the name of drug, pricing and strength) 2) Help-seeking advertisements (only information about a disease or condition without mentioning a particular treatment) 3) Product-claim advertisements (the indication, efficacy and safety information) ${ }^{52-55}$. Pharmaceutical promotion should have both informative and persuasive elements ${ }^{56}$.

DTCPA has several advantages like; educating, encouraging patients to contact a clinician, promotes patient dialogue with doctors, strengthens a patient's relationship with a clinician, encourages patient compliance, reduces underdiagnoses and under treatment of conditions and encourages product competition and lower prices ${ }^{57-58}$.

On the other hand, DTCPA has also some disadvantages which include misinforming patients, overemphasizing drug benefits, encouraging drug overutilization, leading to inappropriate prescribing, wasting appointment time, nonrigid regulations and increasing costs ${ }^{59-60}$.

For example; rofecoxib (Vioxx, Merck) was promoted but its side effects were neglected during advertising. After the discovery of serious side effects of Vioxx, it has been withdrawn from the market. Some heavily promoted drugs such as the diet pills Pondimin and Redux have been also withdrawn due to their potential harm ${ }^{61-63}$.

Even though DTCA is a major factor in patient perception or awareness of cer- 
tain medications, promotional activities directed at the medical community and particularly the promotion of free samples of medications are noted as the most effective means of influencing a physician's prescribing decisions ${ }^{53,64}$.

In some studies, it is shown that consumers attend to and rely on advertising less and respond more to emotional ads than to information ads ${ }^{65}$.

There has been an increase in the use of the Internet for prescription drug promotion which is an evolving area of interest for the pharmaceutical industry and regulators ${ }^{66}$.

DTC marketing can be made in the US even for prescription drugs. The biggest danger here is that the consumer is more interested in attractive promotional messages and ignore the warnings in prescription drugs. Previous studies have shown that $33 \%$ of DTC advertising did not present accurate and balanced explanation of risks and benefits and only $12 \%$ of DTC presented useful information (drug interaction, overdose, etc.) for the consumer. For this reason, companies should focus on giving information to the customers rather than attracting them ${ }^{67-68}$.

It is of course important that the public be informed about health, but the main problem is the content of the advertisement given as information.

On the other hand, unethical strategies such as the astroturfing are also applied by pharmaceutical companies in some countries where DTCA is banned ${ }^{69}$.

As it turns out, potential ethical problems in pharmaceutical branding can be expected to arise in the future ${ }^{70-71}$. Finally, World Health Organisation's (WHO) ethical criteria for pharmaceutical promotion should be taken into consideration in this review. WHO states that all promotion-making claims concerning medicinal drugs should be reliable, accurate, truthful, informative, balanced, up-to-date, capable of substantiation and in good taste. They should not contain misleading or unverifiable statements or omissions likely to induce medically unjustifiable drug use or to give rise to undue risks ${ }^{72}$.

\section{CONCLUSION}

It can be concluded that on the supply side, branding plays an increasingly important role for the pharmaceutical industry. The availability of the internet will create far greater public knowledge about pharmaceutical products and healthcare. On the demand side, patients have become strong advocates of their own healthcare as increasingly undertaking their research. In short, marketers need to fully understand the psychology of illness and consumers' health beliefs about therapeutic categories before creating an advertising campaign.

It should not be forgotten that side effects are a part of every drug. However, they 
are never part of the brand.

For non-prescription drugs, pharmaceutical companies use the same branding techniques as FMCG marketers. On the other hand, branding of prescription drugs have a potential risk ahead. In branding process, marketers should ensure balance of message instead of mass promotion. The best way to achieve this balance is by taking responsibility to the public to act in an ethical manner.

Even if in this circumstance, marketers can build a successful pharmaceutical brand. They have new tools for the communication. In an increasingly networked environment and power of patients, companies should focus on fewer product advertisements and more educational events aimed at raising awareness of a disease.

Overall, this reviewed literature on pharmaceutical branding suggests that it will be possible to develop pharmaceutical brands in a way to promote trust in the product.

\section{REFERENCES}

1. Maurya, U.K.; Mishra, P. What is a brand? A Perspective on Brand Meaning. Eur J Bus Manag. 2012, 4(3), 122-133.

2. Kotler, P.; Armstrong, G.; Saunders, J.; Wong, V. Principles of Marketing, Harlow: Pearson Education Limited, 2001.

3. Schuiling, I.; Moss, G. How different are branding strategies in the pharmaceutical industry and the fast-moving consumer goods sector? BM. 2004, 11(5), 366-380.

4. Blackett, T.; Robins, R. Brand medicine: the role of branding in the pharmaceutical industry. Springer, 2001.

5. Budac, C.; Baltador, L. The value of brand equity. Procedia Econ. Financ. 2013, 6, 444-448.

6. Blackett, T.; Harrison, T. Brand Medicine: Use and Future Potential of Branding in Pharmaceutical Markets. J Med Market. 2001, 2(1), 33-49.

7. Moss, G.; Schuiling, I. A brand logic for pharma?: A possible strategy based on FMCG experience. Int J Med Market. 2004, 4(1), 55-62.

8. Gómez-Suárez, M.; Martínez-Ruiz, M.P.; Martínez-Caraballo, N. Consumer-Brand Relationships under the Marketing 3.o Paradigm: A Literature Review. Front Psychol. 2017, 8.

9. Kotler, P. Marketing Management, millennium edition: Custom Edition for University of Phoenix, 2012.

10. Starzewski, J. H. Quality and the brand management of medicines. JBM. 1993, 1(1), 7-13.

11. Hoeffler, S.; Keller, K.L. The marketing advantages of strong brands. JBM. 20o3, 1O(6), $421-45$.

12. Keller, K.L. Building strong brands in a modern marketing communications environment. $J$ Market Comm. 2009, 15(2-3), 139-155.

13. Crittenden R. Prebiotics and probiotics-the importance of branding. Microb Ecol Health 
Dis. 2012, 23(1), 18566.

14. Moss, G.D. Pharmaceuticals-Where's the Brand Logic?: Branding Lessons and Strategy. CRC Press, 2016.

15. Weston, E. A drug by any other name: brand power in the pharmaceutical industry. New Doct. 1999, 71, 2-11.

16. Abel, G.A.; Penson, R.T.; Joffe, S.; Schapira, L.; Chabner, B.A.; Lynch, T.J. Direct-to-consumer advertising in oncology. Oncologist. 2006, 11(2), 217-226.

17. Silversides, A.A. Direct-to-consumer advertising will erode health care. Can Med Assoc J. 2008, 178(9), 1126-1127.

18. Morgan, S.G. Direct-to-consumer advertising and expenditures on prescription drugs: A comparison of experiences in the United States and Canada. Open Med. 2007, 1(1), 37-45.

19. Chandler, J.; Owen, M. Pharmaceuticals: the new brand arena. Int J Market Res. 2002 , 44(4), 385-406.

20. Dogramatzis, D. Pharmaceutical marketing: a practical guide. Taylor \& Francis US, 2015.

21. Bednarik, J. Does brand differentiate pharmaceuticals? Neuro Endocrinol Lett. 2oo5, 6(26), 636-652.

22. Shamma, H.; Hassan, S. Integrating product and corporate brand equity into total brand equity measurement. Int $J$ Market Stud. 2011, 3(1), 11-20.

23. Bianco, A. The vanishing mass market. Bus Week. July 12 2004, 60-8.

24. Pendleton, J. Multi taskers. Advert Age. 2004, 75(13), 1-8.

25. Schau, H.J.; Muniz A.M.; Arnould E.J. How brand community practices create value. $J$ Mark. 2009, 73(5), 30-51.

26. Griffiths, S. Pharmaceutical branding: 'To brand or not to brand'. J Med Market. 2oo8, 8(2), 113-118.

27. Battistoni E.; Colladon A.F.; Puglia P. Exploiting the potential value of Over-the-Counter drugs through brand equity: An analytic network process approach. IJEBM Special Issue: Innovations in Pharmaceutical Industry. 2014, 6(20), 1-9.

28. Hansen, J.C.; Carpentier, J.P.; Modicom, S. Medical brand vs. medicinal product communication in the healthcare market. J Commun Healthc. 2011, 4(1), 27-37.

29. Aaker, D.A.; Joachimsthaler E. Brand Leadership. London. The Free Press, 200.

30. Delgado-Ballester, E.; Munuera-Aleman, J. Brand trust in the context of consumer loyalty. Eur J Market. 2001, 35(11/12), 1238-1258.

31. Hellman, A.; Gobé, M.; Desgrippes, J. Joël Desgrippes and Marc Gobé on the emotional brand experience. Rockport Publishers, 1, 2007.

32. Ellery, T.; Hansen, N. Pharmaceutical Lifecycle Management: Making the Most of Each and Every Brand, John Wiley \& Sons, Inc., 2012.

33. Roblek, V.; Bertoncelj, A. Impact of corporate social responsibility on OTC medicines consumers. ASE. 2014, 35(16), 12-25.

34. Pilling D. Trust me, I'm a drug salesman: Pharmaceuticals. The Financial Times. Oct 24, 2000. 
35. Hall, D.V.; Jones, S.C. Branding of prescription medicines to Australian consumers. $A M J .15(2), 97-107,2007$.

36. Brunello, A. The relationship between integrated marketing communication and brand equity. Int J Comm Res. 2013, 3(1), 9.

37. Mulhern, F. Integrated marketing communications: From media channels to digital connectivity. J Market Comm. 2009, 15(2-3), 85-101.

38. Gibson, A. The emerging role of integrated marketing in the pharmaceutical industry. JIMC. 2002, 2003, 23-28.

39. Hall, D.V.; Jones, S.C. Direct-to-consumer branding of prescription medicines in Australia, 2006.

40. Evans, W.D.; Blitstein, J.; Vallone, D.; Post, S.; Nielsen, W. Systematic review of health branding: growth of a promising practice. Transl Behav Med. 2015, 5(1), 24-36.

41. Long, T.; Taubenheim, A. M.; Wayman, J.; Temple, S.; Ruoff, B.A. The Heart Truth: Using the power of branding and social marketing to increase awareness of heart disease in women. Soc Mar Q. 2008, 14(3), 3-29.

42. Woloshin, S.; Schwartz, L. M. Giving legs to restless legs: a case study of how the media helps make people sick. PLoS Med. 2006, 3(4), 170.

43. Dickov, V.; Dickov, A.; Martinović-Mitrović, S. The issue of applying marketing on the pharmaceutical market in Serbia. Eur Rev Med Pharmacol Sci. 2011, 15(3), 275-83.

44. Herskovitz, S.; Malcolm, C. The essential brand persona: storytelling and branding. J Bus Strat. 2010, 31(3), 21-28.

45. Simmons, J. Guinness and the role of strategic storytelling. J Strat Market. 20o6, 14(1), 11-18.

46. Fog, K.; Budtz, C.; Yakaboylu, B. Storytelling - Branding in Practice. Berlin Heidelberg: Springer-Verlag, 2005 .

47. Kaufman, B. Stories that sell, stories that tell. J Bus Strat. 2oo3, 24(2), 11-15.

48. Lundqvist, A.; Liljander, V.; Gummerus, J.; Van Riel, A. The impact of storytelling on the consumer brand experience: The case of a firm-originated story. BM. 2013, 2O(4), 283-297.

49. Escalas, J.E. Narrative processing: Building consumer connections to brands. $J$ Consum Psychol. 2004, 14(1-2), 168-179.

50. Chiu, H. C.; Hsieh, Y.C.; Kuo, Y.C. How to align your brand stories with your products. $J$ Retailing. 2012, 88(2), 262-275.

51. Teixeira, T.S. The rising cost of consumer attention: why you should care, and what you can do about it, 2014.

52. Connors, A.L. Big Bad Pharma: An ethical analysis of physician-directed and consumerdirected marketing tactics. Alb L Rev. 2009, 73(1), 243.

53. Ventola, C.L. Direct-to-consumer pharmaceutical advertising: therapeutic or toxic? P \& T. 2011, 36(10), 669-684.

54. Gellad, Z.F.; Lyles, K.W. Direct-to-Consumer Advertising for Pharmaceuticals. The Am J Med. 2007, 120(6), 475-480.

55. Findlay S.D. Direct-to-consumer promotion of prescription drugs. PharmacoEconomics. 
2001, 19(2), 109-19.

56. Dave, D.M. Pharmaceutical Marketing and Promotion. Encyclopedia of Health Economics. 2014, 9-19.

57. Lewin, B. Patient satisfaction with physician responses during interactions prompted by pharmaceutical advertisements. The Soc Sci J. 2013, 5O(4), 491-500.

58. Weissman, J.S.; Blumenthal, D.; Silk, A.J.; Newman, M.; Zapert, R.; Leitman, R.; Feibelmann, S. Physicians report on patient encounters involving direct-to-consumer advertising. Health Aff. 2004, W4.

59. Robinson, A.R.; Hohmann, K.B.; Rifkin, J.I.; Topp, D.; Gilroy, C.M.; Pickard, J.A.; Anderson, R.J. Direct-to-consumer pharmaceutical advertising: physician and public opinion and potential effects on the physician patient relationship. Arch Intern Med 2004, 164(4), 427-432.

6o. Liang, B.A.; Mackey, T. Direct-to-consumer advertising with interactive Internet media: Global regulation and public health issues. JAMA. 2011, 305(8), 824-825.

61. Schuchman, M. Drug risks and free speech: Can Congress ban consumer drug ads? N Engl $J$ Med. 2007, 356(22), 2236-2239.

62. Donohue, J.; Cevasco, M.; Rosenthal, M. A Decade of Direct-to-Consumer Advertising of Prescription Drugs. N Engl J Med. 2007, 673-681.

63. Arnold, D.G.; Oakley, J.L. The politics and strategy of industry self-regulation: the pharmaceutical industry's principles for ethical direct-to-consumer advertising as a deceptive blocking strategy. J Health Polit Pol Law. 2013, 38(3), 505-544.

64. Schultz, S.A.; Broekmier, G.M.; Burnkink, T.J. Attitudes and Beliefs Regarding Direct-toConsumer Advertising of Pharmaceutical Drugs: An Exploratory Comparison of Physician and Pharmaceutical Sales Representatives. Health Market Q. 2014, 279-291.

65. DeLorme, D.; Huh, J.; Reid, L. Direct-to-Consumer Advertising Scepticism and the Use and Perceived Usefulness of Prescription Drug Information Sources. Health Market Q. 2oo9, 293-314.

66. Sullivan, H.; Campbell, M. Do Prescription Drug Ads Tell Consumers Enough About Benefits and Side Effects? Results from the Health Information National Trends Survey, Fourth Administration. J Health Comm. 2015, 1-6.

67. Main, K.J.; Argo, J.J.; Huhmann, B.A. Pharmaceutical advertising in the USA: Information or influence? Int J Advert. 2004, 23, 119-142.

68. Roth M. Patterns in direct-to-consumer prescription drug print advertising and their public policy implications. JPP\&M. 1996, 15, 63-75.

69. Shir-Raz Y.; Avraham E. "Under the regulation radar": PR strategies of pharmaceutical companies in countries where direct advertising of prescription drugs is banned-The Israeli case. Public Relat Rev. 2017, 43(2), 382-391.

70. Anker, T.B.; Sandøe, P.; Kamin, T.; Kappel, K. Health branding ethics. J Bus Ethics. 2011, 104(1), 33-45.

71. Verschoor, C.C. Ethics issues still dog pharmaceutical industry. Strat Finance. 2oo7, 88(11), 17.

72. World Health Organization. Ethical criteria for medicinal drug promotion. Geneva, 1988. 